\title{
The HIV-Brazil Cohort Study: Design, Methods and Participant Characteristics
}

\author{
Alexandre Grangeiro ${ }^{1 *}$, Maria Mercedes Escuder ${ }^{2}$, Alex Jones Flores Cassanote ${ }^{3}$, Rosa Alencar Souza ${ }^{4}$, \\ Artur O. Kalichman ${ }^{4}$, Valdiléa Veloso ${ }^{5}$, Maria Letícia Rodrigues Ikeda ${ }^{6}$, Nêmora Tregnago Barcellos ${ }^{6}$, \\ Carlos Brites ${ }^{7}$, Unai Tupinanbás ${ }^{8}$, Noaldo O. Lucena9 ${ }^{9}$, Carlos Lima da Silva ${ }^{10}$, Heloisa Ramos Lacerda ${ }^{11}$, \\ Beatriz Grinsztejn ${ }^{5}$, Euclides Ayres Castilho'
}

1 Department of Preventive Medicine, University of São Paulo School of Medicine, São Paulo, Brazil, 2 Health Institute, São Paulo State Department of Health, São Paulo, Brazil, 3 Postgraduate Program in Infectious and Parasitic Diseases, University of São Paulo School of Medicine, São Paulo, Brazil, 4 STD/AIDS Referral and Training Centre, São Paulo State Department of Health, São Paulo, Brazil, 5 Evandro Chagas Clinical Research Institute, Oswaldo Cruz Foundation, Rio de Janeiro, Brazil, 6 Care and Treatment Clinic of the Partenon Sanatorium, Rio Grande do Sul State Department of Health, Porto Alegre, Brazil, 7 Edgar Santos University Hospital Complex, Federal University of Bahia, Salvador, Brazil, 8 Medical School, Federal University of Minas Gerais, Belo Horizonte, Brazil, 9 Tropical Medicine Foundation, Amazonas State Department of Health, Manaus, Brazil, 10 State Centre for Diagnosis, Treatment and Research, Bahia State Department of Health, Salvador, Brazil, 11 Federal University of Pernambuco, Recife, Brazil

\begin{abstract}
Background: The HIV-Brazil Cohort Study was established to analyze the effectiveness of combination antiretroviral therapy (CART) and the impact of this treatment on morbidity, quality of life (QOL) and mortality. The study design, patients' profiles and characteristics of CART initiation between 2003 and 2010 were described.

Methodology/Principal Findings: Since 2003, the HIV-Brazil Cohort has been following HIV-infected adults receiving cART at 26 public health care facilities, using routine clinical care data and self-reported QOL questionnaires. When not otherwise available, data are obtained from national information systems. The main outcomes of interest are diseases related or unrelated to HIV; suppression of viral replication; adverse events; virological, clinical and immunological failures; changes in the CART; and mortality. For the 5,061 patients who started CART between 2003 and 2010, the median follow-up time was 4.1 years (IQR 2.2-5.9 years) with an 83.4\% retention rate. Patient profiles were characterized by a predominance of men (male/female ratio 1.7:1), with a mean age of 36.9 years (SD 9.9 years); $55.2 \%$ had been infected with HIV via heterosexual contact. The majority of patients (53.4\%) initiated cART with a CD4 ${ }^{+}$T-cell count $\leq 200 \mathrm{cells} / \mathrm{mm}^{3}$. The medications most often used in the various treatment regimens were efavirenz (59.7\%) and lopinavir/ritonavir (18.2\%). The proportion of individuals achieving viral suppression within the first 12 months of cART use was $77.4 \%(95 \% \mathrm{Cl} 76.1-78.6)$. Nearly half $(45.4 \%)$ of the patients presented HIV-related clinical manifestations after starting CART, and the AIDS mortality rate was 13.9 per 1,000 person-years.
\end{abstract}

Conclusions/Significance: Results from CART use in the daily practice of health services remain relatively unknown in lowand middle-income countries, and studies with the characteristics of the HIV-Brazil Cohort contribute to minimizing these shortcomings, given its scope and patient profile, which is similar to that of the AIDS epidemic in the country.

Citation: Grangeiro A, Escuder MM, Cassanote AJF, Souza RA, Kalichman AO, et al. (2014) The HIV-Brazil Cohort Study: Design, Methods and Participant Characteristics. PLoS ONE 9(5): e95673. doi:10.1371/journal.pone.0095673

Editor: Andrew Boulle, Faculty of Health Sciences, University of Cape Town, South Africa

Received September 23, 2013; Accepted March 30, 2014; Published May 1, 2014

Copyright: ( 2014 Grangeiro et al. This is an open-access article distributed under the terms of the Creative Commons Attribution License, which permits unrestricted use, distribution, and reproduction in any medium, provided the original author and source are credited.

Funding: The study is funded by the Brazilian National Council for Scientific and Technological Development, the Brazilian National Ministry of Health, the Pan American Health Organization, the STD/AIDS Referral and Training Centre of the São Paulo State Department of Health and the Evandro Chagas Clinical Research Institute of the Oswaldo Cruz Foundation. The funders had no role in study design, data collection and analysis, decision to publish, or preparation of the manuscript.

Competing Interests: The authors declare that the co-author Beatriz Grinsztejn is a PLOS ONE Editorial Board member. This does not alter the authors adherence to all the PLOS ONE policies on sharing data and materials.

* E-mail: ale.grangeiro@gmail.com

\section{Introduction}

In 1996, Brazil adopted a policy of universal access to combination antiretroviral therapy (cART), which was free of charge to human immunodeficiency virus (HIV)-infected individuals. Since then, immunological and virological treatment monitoring, as well as genotype-resistance testing for treatment failure management, have been incorporated into that policy. As of 2012, approximately 217,000 patients in Brazil were being treated with first-, second- or third-line antiretroviral therapy, including newer antiretroviral options for salvage therapy management, leading to an overall reduction in the morbidity and mortality associated with HIV infection [1-5].

In recent years, there has been a reduction in the magnitude of the impact that opportunistic diseases have had on morbidity and mortality in cART patients in Brazil, although there has been an increase in the incidence of complications unrelated to infection by HIV, such as cardiovascular events, impaired renal function, liver 
disease and neoplasia [2,6-12]. These complications occur in the context of both long-term exposure to cART and the rapid demographic transition that is underway in Brazil, which has resulted in an increase in the number of $\mathrm{HIV}$-infected people over the age of 50 [13].

The impact of the Brazilian policy has been the object of nationwide studies, mostly focused on mortality $[9,10,14,15]$, the impact on the health system $[1,5,16]$ and HIV resistance surveillance $[17,18]$, as well as small studies with limited representativeness, evaluating the clinical aspects of HIV infection $[8,11,19]$ and the use of cART $[20-24]$. However, to date, there have been no nationwide longitudinal studies providing a broader picture of the Brazilian HIV epidemic and the results of the national HIV policy.

Furthermore, recently, important changes have occurred in the use of cART therapy due to the proven efficacy of these drugs to reduce the risk of acquiring and transmitting HIV infection, as well as increased evidence that early initiation of cART has significant health benefits [25-30]. This new context has fuelled the debate regarding the feasibility of achieving effective control over the HIV/AIDS epidemic in the near future [31].

These circumstances increase the relevance of studies assessing the various dimensions of access to diagnosis and treatment of HIV infections; the efficacy and effectiveness of such treatment; and the impact of this treatment on morbidity, mortality, and QOL. Therefore, the HIV-Brazil Cohort Study was established to gather further knowledge on the context of the Brazilian epidemic and to generate scientific evidence to make informed decisions regarding the planning and implementation of public policies, taking into consideration the regional disparities, as well as the specificities of the Brazilian population and of the national health care system [32]. The aim of this paper is to present the design and scope of the HIV-Brazil Cohort Study and the profile and initial cART of enrolled patients.

\section{Methods}

\section{Cohort Sites}

There are 13 sites participating in the study, involving 26 public health facilities in 11 cities across four of the five regions of the country (Figure 1). The facilities were selected based on convenience, by region and city of location, the availability of information on the clinical follow-up and use of cART, and the existing infrastructure to conduct studies of this nature. The cities in which these facilities are located (Table 1) were chosen because they are representative of the diversity of the epidemiological profile of AIDS in Brazil [33] and account for 28\% of all AIDS cases diagnosed in the country. Information regarding epidemiological surveillance derived by the Ministry of Health (Table 1) shows that, in 6 of the 11 cities, the incidence of AIDS cases is progressively increasing, having risen by an average of $30.7 \%$ from 2001 to 2010; in 7 of the cities, heterosexual transmission is the predominant route of HIV infection (in $>60 \%$ of cases); and 6 of the cities are located in lower-income regions of the country (North or Northeast).

The number of patients under treatment at the participating sites ranged from 519 (at the Jaboatão de Guararapes Municipal Specialised Outreach Clinic) to 34,932 (within the São Paulo Municipal Network), with 7 of the 13 sites being responsible for treating more than half of the AIDS cases identified in their municipalities. Across the 13 sites, the mean ratio of outpatients to infectious disease specialists or general clinicians is 299:1 (SD 158.8; range 77-706). Among the patients on cART, the interval between clinical consultations has ranged from 3 to 6 months, and
6 of the 13 sites have adopted outreach strategies for patients who miss appointments (Table 1).

At most of the sites (Table 1), the health care infrastructure includes other services, such as centers for the diagnosis of HIV infection (at all 13 sites), pharmacies (also at all 13 sites) and laboratories for monitoring HIV infection (at 7 sites), as well as inpatient units (at 6 sites) and home care services (at 4 sites).

\section{Eligibility and Inclusion Criteria}

As of November 2012, 6,109 HIV-infected adults ( $\geq 18$ years of age) had been enrolled in the cohort. All the included individuals had initiated antiretroviral treatment on or after January 1, 2003 (median year 2007; IQR 2004-2008), and had had at least one clinical follow-up appointment after treatment initiation. The inclusion occurred in two phases. Between 2009 and 2011, patients who had been started on cART between January 2003 and December 2010 were enrolled, whereas in the second phase, patients who had been started on cART on or after 1 January 2011 were enrolled. The first phase was aimed at observing events of interest that had occurred before the patients had been included in the cohort (retrospective phase), and the second phase was aimed at observing such events as they occurred, over the course of follow-up performed as routine clinical outpatient services (prospective phase).

Table 1 shows the sites involved in each phase and the procedures used in the selection of patients. At 8 of the 13 sites, eligible patients were identified from the total number of patients in clinical follow-up at each site, via an electronic cART dispensing system, and all such patients were included. At the 5 remaining sites, a non-probabilistic sample was used, with the selection procedures differing from site to site, depending on the features of the systems used for registering the cART dispensation. To identify possible discrepancies, the characteristics of the nonprobabilistic samples at each site were compared with those of patients in the cohort already established for the region in which the site is located. For this comparison, patients included in the non-probabilistic samples were excluded from the set of individuals in the regional cohort. Similarities in terms of gender, age and lowest recorded $\mathrm{CD} 4^{+} \mathrm{T}$-cell count were observed. The principal differences observed were that the proportion of females was greater in the non-probabilistic sample of the São Paulo Municipal Network than in the patients of the southeastern cohort $(36.4 \%$ vs. $31.8 \%$ ) and that the mean $\mathrm{CD}^{+}{ }^{+} \mathrm{T}$-cell count was higher in the non-probability sample of the Federal University of Minas Gerais than in the patients of the southeastern cohort $\left(204.2\right.$ cells $/ \mathrm{mm}^{3}$ vs. 174.2 cells $/ \mathrm{mm}^{3}$ ).

\section{Data Sources and Outcomes}

The cohort data were obtained as part of the routine clinical care provided at the health service centers included (routine-care based cohort) and were abstracted from the patients' clinical records by trained abstractors onto standardized forms. These clinical records were reviewed at intervals not exceeding six months to investigate events recorded during the routine clinical follow-up visits performed within each period. To determine the consistency and completeness of the information, the forms were checked at the cohort coordination level. Approximately $5 \%$ of the forms were crosschecked against the information in the clinical records. From 2012 on, information has been collected using an online system developed on the Research Electronic Data Capture platform [34].

Information on QOL started being collected in 2011, using the World Health Organization self-report questionnaire (QOL Instrument-HIV, brief version) validated for use in Brazil [35]. 


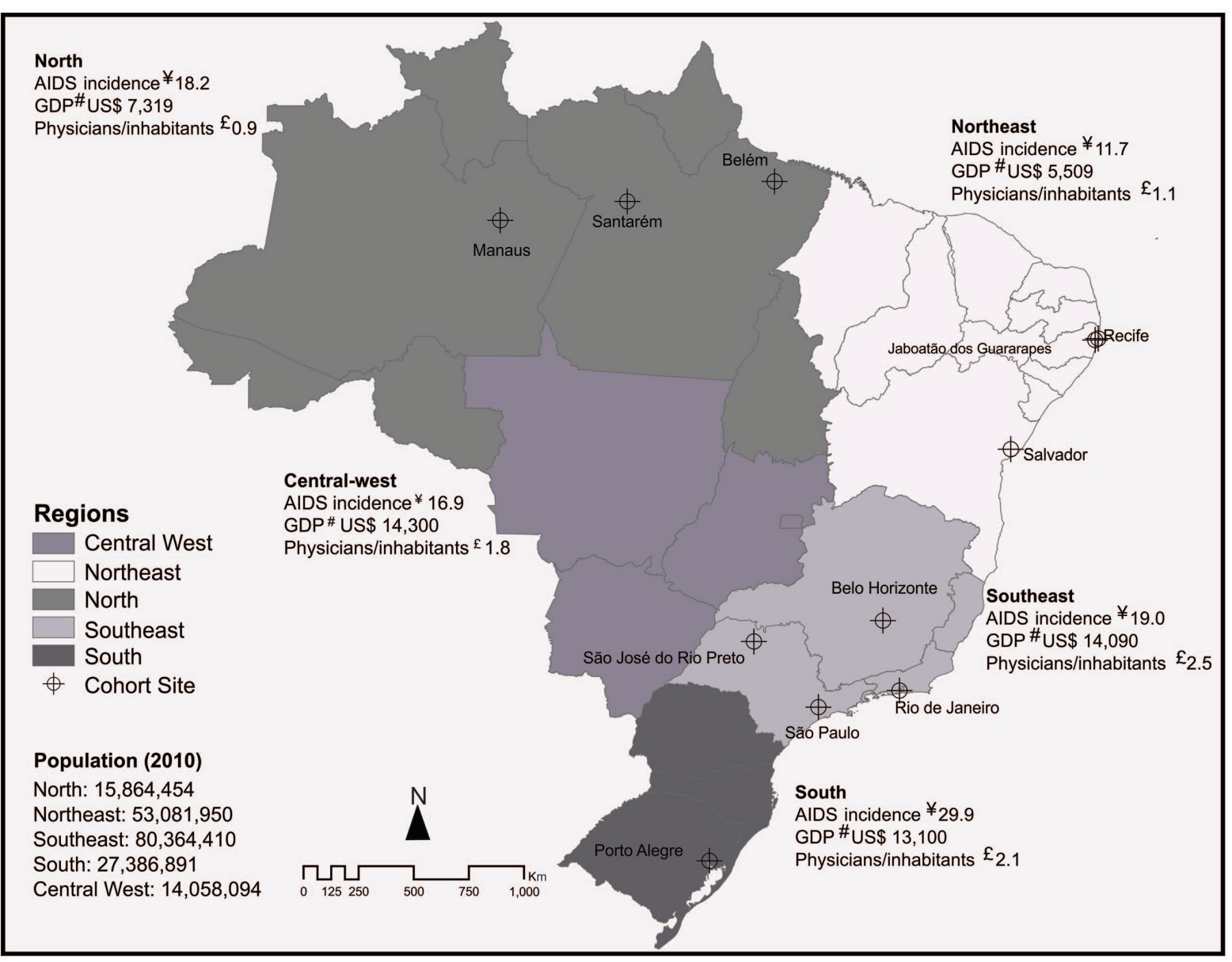

Figure 1. Characteristics of the regions and sites in the HIV-Brazil Cohort Study. Notes: $¥$ Means per 100000 population (2006 to 2010 ); \#Per capita gross domestic product (2010); $£$ number of physicians per 1000 inhabitants (2010). Source: Ministry of Health/DATASUS (Information Technology Department of the Brazilian National Health Care System) and the Brazilian Institute of Geography and Statistics. doi:10.1371/journal.pone.0095673.g001

The questionnaire is applied at follow-up initiation and every 12 months after the initiation of cART. Information about the treatment facilities, as well as the appropriateness and quality of the participant's enrollment and data collection procedures, are obtained periodically through an electronic form completed at the sites.

The main outcomes of interest are the occurrence of diseases related or unrelated to HIV; suppression of viral replication (viral load $<400$ copies/ml [2003 to 2006] and $<50$ copies/ml [after 2007]); antiretroviral treatment modifications (initial or subsequent regimen); treatment failure (virological, clinical or immunological failure); adverse events; and death. Clinical and epidemiological data were collected for the entire clinical follow-up period, including socio-demographic data; HIV transmission category; use of illicit drugs, alcohol and tobacco; individual or family history of metabolic disorders, hypertension or cardiovascular disease; AIDS-related and non-AIDS-related manifestations; initial and subsequent cART regimens used for prophylaxis and treatment; occurrence of adverse events related to the use of cART, prophylaxis for opportunistic diseases and vaccines; CD4, viral load and genotyping results, as well as safety laboratory tests for cART monitoring; and mortality.

To enhance the level of completeness, missing data-notably, demographic data, $\mathrm{CD} 4^{+} \mathrm{T}$-cell counts, viral load and mortality data-were systematically checked across the national information systems.

\section{Censoring Criteria}

Individuals were censored in case of loss of clinical follow-up, relocation for follow-up in another clinical setting or death. To check the status of patients in the cohort, those categorized as lost to clinical follow-up were traced in the national information systems managed by the Brazilian National Ministry of Health: the National $\mathrm{CD}^{+} / \mathrm{CD}^{+} \mathrm{T}$ Lymphocyte Count and Viral Load Network Laboratory Test Control System (for CD4 ${ }^{+}$T-cell counts and viral loads); the National System for the Logistic Control of Medications (for information regarding the dispensing of cART); and the National Mortality Information System (for mortality data). The screening was conducted annually, through electronic matching, checking for perfect combinations of key fields (patient's name, mother's name and date of birth). Patients not located through this procedure were then investigated using an alphabetically sorted list.

Loss of follow-up was defined as an absence of patient contact with the health care center for more than 12 months (i.e., no consultations, no CD4 or viral load exams performed, no records related to ARV refills in the clinical records) and the nonidentification of the patient in the national information systems, as described above, up to July 2011. Patients were classified as having 


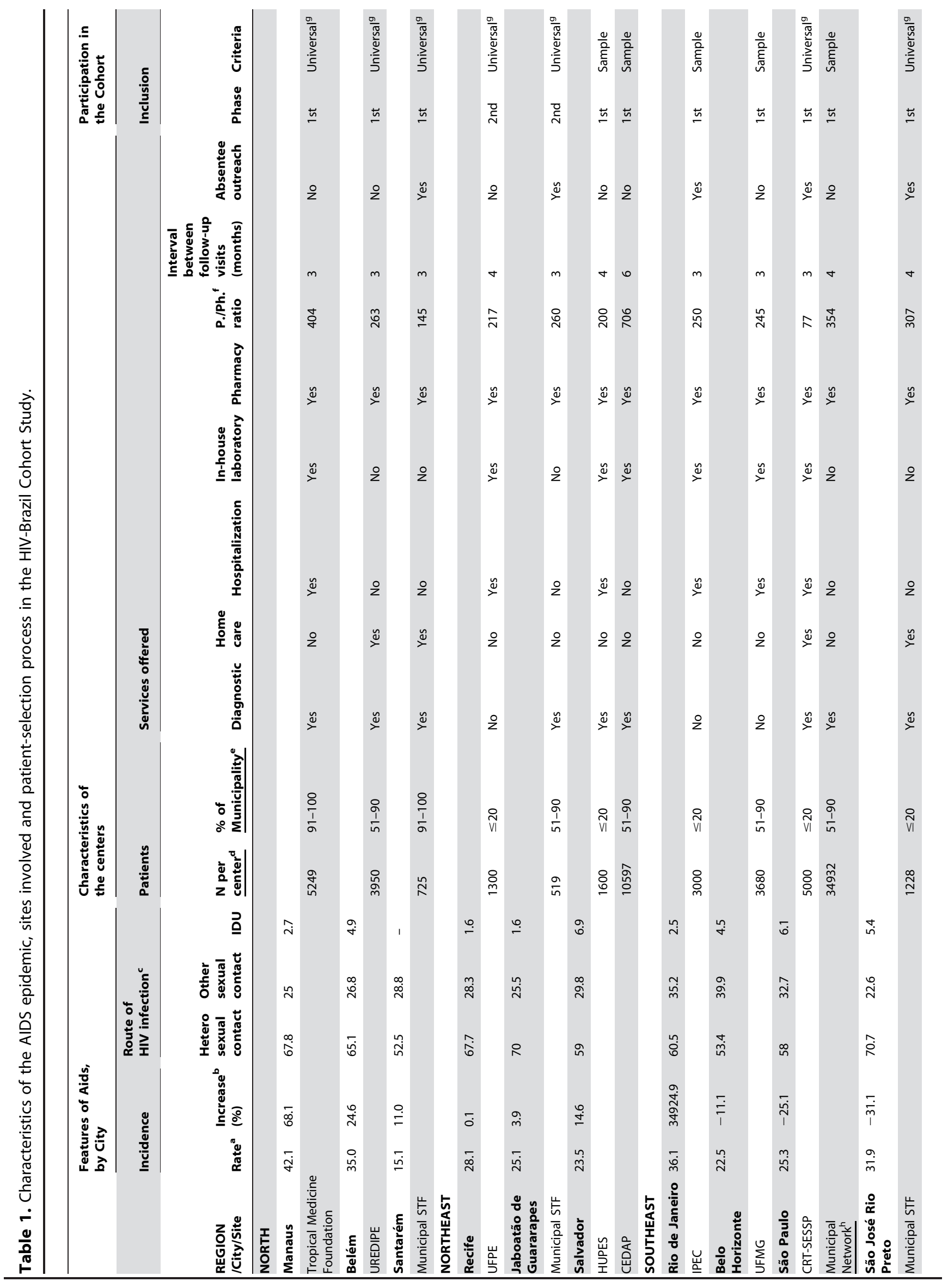




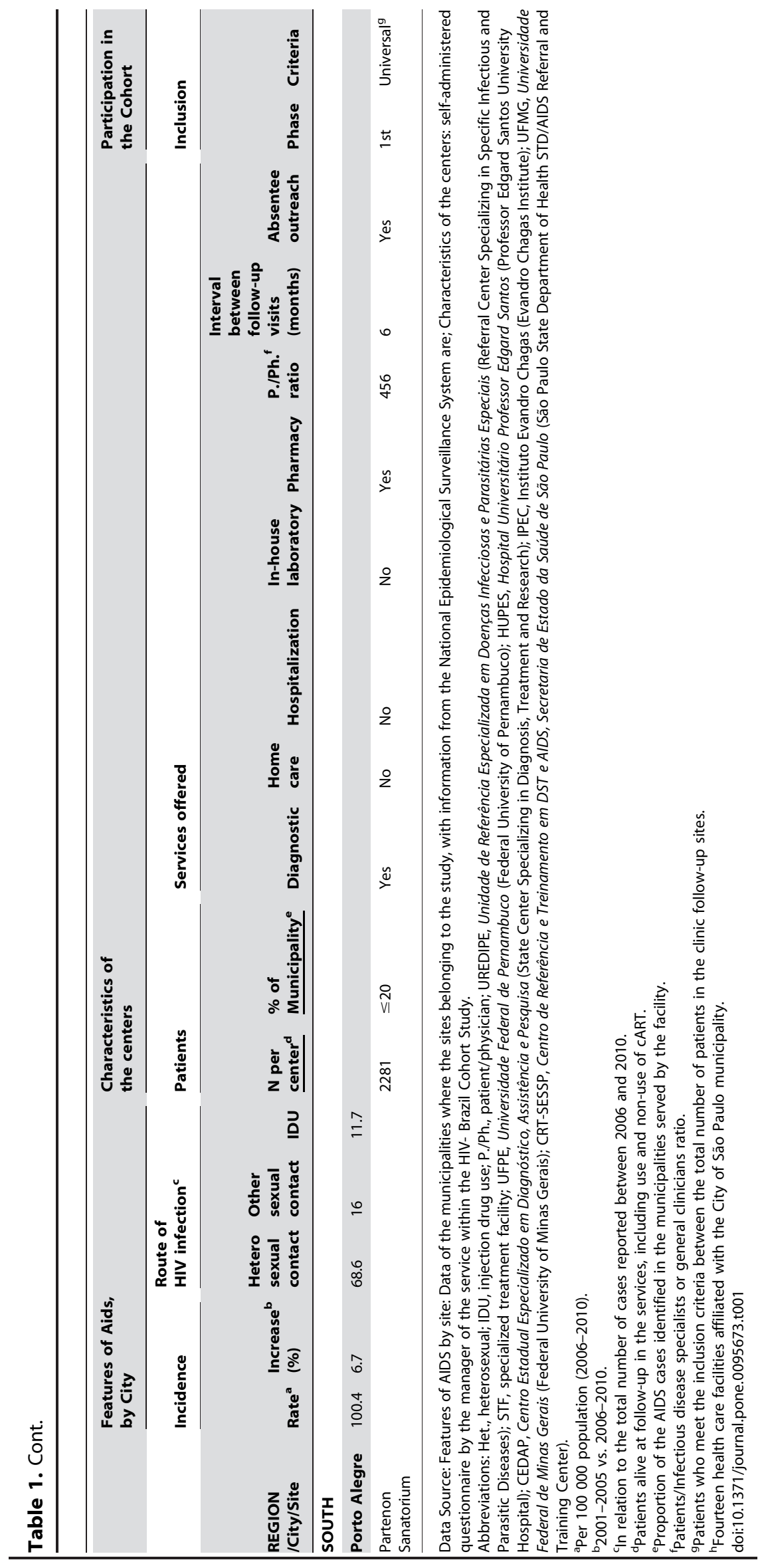


Table 2. Characteristics of the patients and AIDS cases reported to the Brazilian Ministry of Health.

\begin{tabular}{|c|c|c|c|c|}
\hline \multirow[t]{3}{*}{ Variable } & \multicolumn{4}{|c|}{ 2003-2010 } \\
\hline & \multicolumn{2}{|c|}{ HIV-Brazil Cohort } & \multicolumn{2}{|c|}{ Reported Cases of AIDS ${ }^{a}$} \\
\hline & $(N)$ & (\%) & $(N)$ & (\%) \\
\hline Brazil (nationwide) & 5061 & 100.0 & 156391 & 100.0 \\
\hline \multicolumn{5}{|l|}{ Region } \\
\hline North & 1366 & 27.0 & 13159 & 8.4 \\
\hline Northeast & 576 & 11.4 & 29448 & 18.8 \\
\hline Southeast & 2300 & 45.4 & 74277 & 47.9 \\
\hline South & 819 & 16.2 & 39505 & 25.3 \\
\hline No data available & - & - & 2 & 0,0 \\
\hline \multicolumn{5}{|l|}{ Gender } \\
\hline Male & 3208 & 63.4 & 95952 & 61.4 \\
\hline Female & 1853 & 36.6 & 60425 & 38.6 \\
\hline No data available & - & - & 14 & 0.0 \\
\hline Male/female ratio & 1.7 & - & 1.7 & 1.6 \\
\hline \multicolumn{5}{|l|}{ Age group (years) } \\
\hline 18 to 25 & 543 & 10.7 & 17708 & 11.3 \\
\hline 26 to 30 & 925 & 18.3 & 25289 & 16.2 \\
\hline 31 to 35 & 1030 & 20.4 & 28067 & 17.9 \\
\hline 36 to 40 & 915 & 18.1 & 26240 & 16.8 \\
\hline 41 to 45 & 711 & 14.0 & 22231 & 14.2 \\
\hline 46 to 50 & 460 & 9.1 & 15588 & 10.0 \\
\hline 51 to 90 & 475 & 9.4 & 21241 & 13.6 \\
\hline No data available & 2 & 0.0 & 27 & 0.0 \\
\hline Age (in years), mean (SD) & 36.9 & & $37.9(10.8$ & \\
\hline \multicolumn{5}{|l|}{ Exposure Category } \\
\hline Heterosexual transmission & 2792 & 55.2 & 66165 & 60.0 \\
\hline Homosexual transmission & 859 & 17.0 & 14408 & 13.1 \\
\hline Bisexual transmission & 334 & 6.6 & 6074 & 5.5 \\
\hline Unspecified sexual transmission ${ }^{\mathrm{b}}$ & 203 & 4.0 & - & - \\
\hline Injection drug use & 183 & 3.6 & 5838 & 5.3 \\
\hline Transfusion of blood or blood products & 87 & 1.7 & 117 & 0.1 \\
\hline Vertical transmission & 18 & 0.4 & 348 & 0.3 \\
\hline No data available & 585 & 11.6 & 17323 & 15.7 \\
\hline \multicolumn{5}{|l|}{ Pre-cART use of cocaine ${ }^{b}$} \\
\hline No & 4318 & 85.3 & - & - \\
\hline Yes & 743 & 14.7 & - & - \\
\hline \multicolumn{5}{|l|}{ Lowest $\mathrm{CD4}^{+} \mathrm{T}$-cell count $\left(\text { cells } / \mathrm{mm}^{3}\right)^{\mathbf{b}}$} \\
\hline$>350$ & 241 & 4.8 & - & - \\
\hline $200+350$ & 1587 & 31.4 & - & - \\
\hline$\leq 200$ & 2704 & 53.4 & - & - \\
\hline No data available & 529 & 10.5 & - & - \\
\hline Nadir CD4 ${ }^{+}$T-cell count (cells $/ \mathrm{mm}^{3}$ ), mean $(\mathrm{SD})^{\mathrm{b}}$ & 177.5 & & - & - \\
\hline \multicolumn{5}{|l|}{ Clinical manifestation at the initiation of CART $^{\mathbf{b}}$} \\
\hline None & 2062 & 40.7 & - & - \\
\hline Signs and symptoms & 1620 & 32.0 & - & - \\
\hline Associated diseases & 1379 & 27.2 & - & - \\
\hline \multicolumn{5}{|l|}{ Initial regimen, by drug class ${ }^{b}$} \\
\hline 2NRTIs+1NNRTI & 3247 & 64.2 & - & - \\
\hline $2 \mathrm{NRTIs+PI/r}$ & 1220 & 24.1 & - & - \\
\hline
\end{tabular}


Table 2. Cont.

\begin{tabular}{|c|c|c|c|c|}
\hline \multirow[t]{3}{*}{ Variable } & \multicolumn{4}{|c|}{ 2003-2010 } \\
\hline & \multicolumn{2}{|c|}{ HIV-Brazil Cohort } & \multicolumn{2}{|c|}{ Reported Cases of AIDS ${ }^{a}$} \\
\hline & $(N)$ & (\%) & $(N)$ & (\%) \\
\hline 2NRTIs+PI & 511 & 10.1 & - & - \\
\hline Other & 83 & 1.6 & - & - \\
\hline \multicolumn{5}{|c|}{ Initial regimen, by drug ${ }^{b}$} \\
\hline $\mathrm{AZT}+3 \mathrm{TC}+\mathrm{EFZ}$ & 2436 & 48.1 & - & - \\
\hline $\mathrm{AZT}+3 \mathrm{TC}+\mathrm{LPV} / \mathrm{r}$ & 724 & 14.3 & - & - \\
\hline$A Z T+3 T C+A T V / r$ & 232 & 4.6 & - & - \\
\hline Other & 1663 & 32.6 & - & - \\
\hline
\end{tabular}

Abbreviations: NRTI, nucleoside analogue reverse transcriptase inhibitor; NNRTI, non-nucleoside analogue reverse transcriptase inhibitor; PI/r, protease inhibitor, with adjuvant ritonavir; AZT, zidovudine; 3TC, lamivudine; EFZ, efavirenz; LPV/r, lopinavir/ritonavir; ATV/r, atazanavir/ritonavir.

${ }^{a}$ In individuals over 18 years of age.

${ }^{\mathrm{b}}$ Data not included on AIDS case reporting form.

doi:10.1371/journal.pone.0095673.t002

been relocated for follow-up in another clinical setting when relocations were noted in the clinical record or when the patients were identified in the information systems as performing their $\mathrm{CD}^{+}{ }^{+} \mathrm{T}$-cell count, viral load determination or ART dispensation elsewhere after the date of the last entry in the clinical record.
AIDS-related deaths were defined as those in which the official record listed AIDS as being the underlying cause of death.

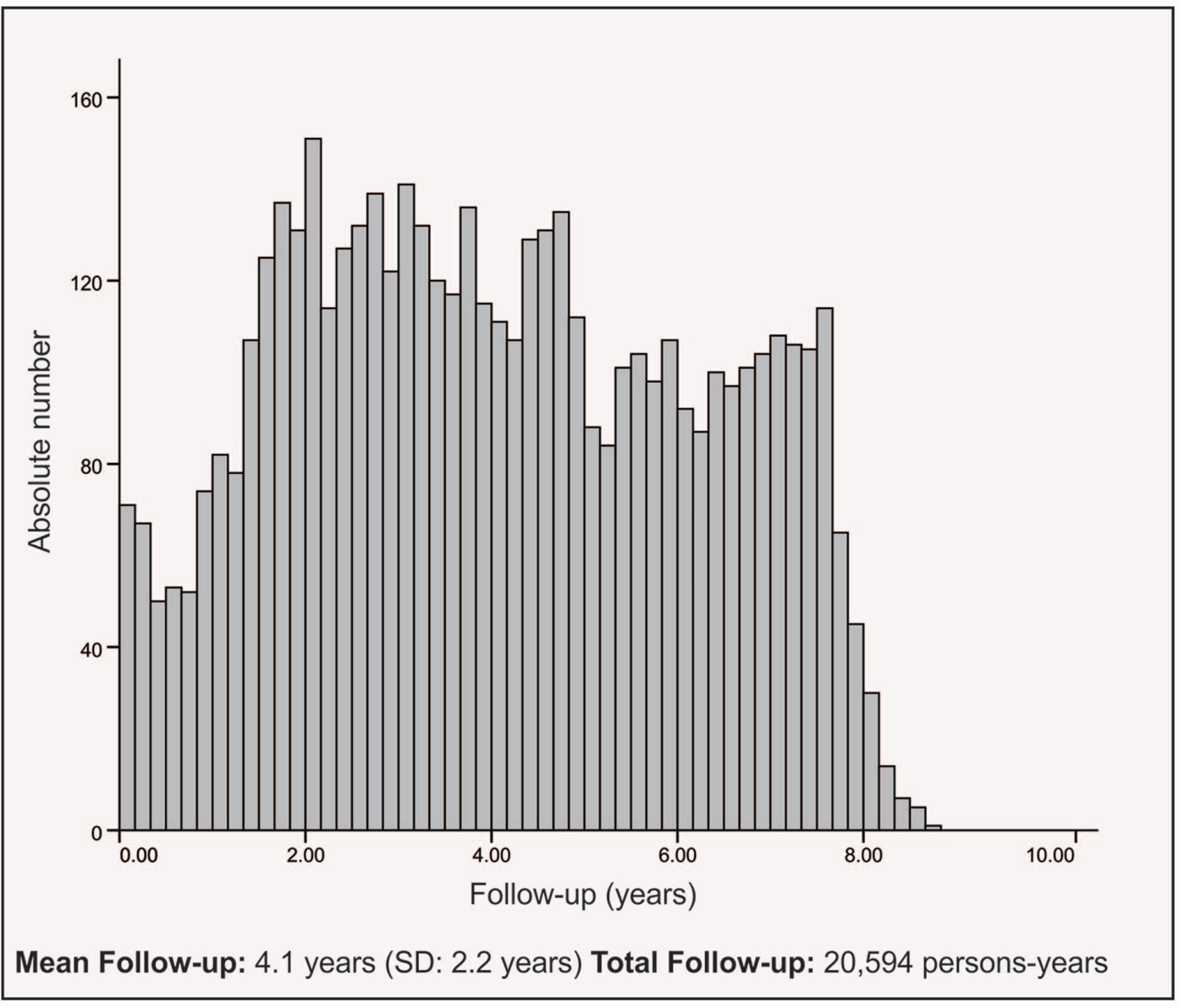

Figure 2. Patients included in the HIV-Brazil Cohort Study by follow-up time. doi:10.1371/journal.pone.0095673.g002 
Table 3. Descriptive analysis of loss of follow-up ${ }^{\mathrm{a}}$ in the HIV-Brazil Cohort Study.

\begin{tabular}{|c|c|c|c|c|c|c|}
\hline \multirow{2}{*}{ Characteristics } & \multirow{2}{*}{$\begin{array}{l}\text { HIV-Brazil Cohort } \\
N\end{array}$} & \multicolumn{2}{|c|}{ Loss of follow-up } & \multicolumn{2}{|c|}{$95 \% \mathrm{Cl}$ of the proportion } & \multirow{2}{*}{ Rate of follow up loss (1000 PY) } \\
\hline & & $N$ & (\%) & Minimum & Maximum & \\
\hline \multicolumn{7}{|l|}{ Gender } \\
\hline Male & 3208 & 147 & 4.6 & 3.9 & 5.4 & 11.4 \\
\hline Female & 1853 & 59 & 3.2 & 2.5 & 4.1 & 7.7 \\
\hline \multicolumn{7}{|l|}{ Sexual Orientation ${ }^{\mathbf{b}}$} \\
\hline Homosexual & 906 & 20 & 2.2 & 1.4 & 3.4 & 5.3 \\
\hline Bisexual & 374 & 21 & 5.6 & 3.7 & 8.4 & 13.8 \\
\hline Heterosexual & 2983 & 113 & 3.8 & 3.2 & 4.5 & 9.1 \\
\hline \multicolumn{7}{|l|}{ Age group (years) ${ }^{b}$} \\
\hline 18 to 25 & 543 & 30 & 5.5 & 3.9 & 7.8 & 14.0 \\
\hline 26 to 30 & 925 & 56 & 6.1 & 4.7 & 7.8 & 15.6 \\
\hline 31 to 35 & 1030 & 43 & 4.2 & 3.1 & 5.6 & 10.1 \\
\hline 36 to 40 & 915 & 27 & 3.0 & 2.0 & 4.3 & 6.9 \\
\hline 41 to 45 & 711 & 30 & 4.2 & 3.0 & 6.0 & 10.3 \\
\hline 46 to 50 & 460 & 6 & 1.3 & 0.6 & 2.8 & 3.2 \\
\hline 51 to 90 & 475 & 12 & 2.5 & 1.5 & 4.4 & 6.3 \\
\hline \multicolumn{7}{|l|}{ Region } \\
\hline North & 1366 & 105 & 7.7 & 6.4 & 9.2 & 21.3 \\
\hline Northeast & 576 & 25 & 4.3 & 3.0 & 6.3 & 10.9 \\
\hline Southeast & 2300 & 63 & 2.7 & 2.1 & 3.5 & 5.9 \\
\hline South & 819 & 13 & 1.6 & 1.3 & 3.2 & 4.9 \\
\hline \multicolumn{7}{|c|}{ Pre-cART clinical manifestation } \\
\hline None & 2062 & 84 & 4.1 & 3.3 & 5.0 & 10.0 \\
\hline Signs and symptoms & 1620 & 70 & 4.3 & 3.4 & 5.4 & 10.7 \\
\hline Associated disease & 1379 & 52 & 3.8 & 2.9 & 5.0 & 9.2 \\
\hline \multicolumn{7}{|c|}{ Post-cART clinical manifestation } \\
\hline None & 2762 & 131 & 4.7 & 4.0 & 5.6 & 12.6 \\
\hline Signs and symptoms & 1311 & 38 & 2.9 & 2.1 & 4.0 & 6.6 \\
\hline Associated disease & 988 & 37 & 3.7 & 2.7 & 5.1 & 8.2 \\
\hline \multicolumn{7}{|c|}{ Pre-cART use of cocaine } \\
\hline Yes & 4318 & 170 & 3.9 & 3.4 & 4.6 & 9.6 \\
\hline No & 743 & 36 & 4.8 & 3.5 & 6.6 & 12.1 \\
\hline \multicolumn{7}{|c|}{ Lowest CD4+ T-cell count $\left(\mathrm{mm}^{3}\right)^{\mathbf{b}}$} \\
\hline$>350$ & 241 & 10 & 4.1 & 2.2 & 7.4 & 8.8 \\
\hline $200 \dashv 350$ & 1587 & 69 & 4.3 & 3.4 & 5.4 & 10.7 \\
\hline$\leq 200$ & 2704 & 97 & 3.6 & 2.9 & 4.3 & 9.9 \\
\hline
\end{tabular}

Abbreviation: PY, person-years.

${ }^{\text {a }}$ Maximum follow-up time of 8.8 years.

${ }^{\mathrm{b}}$ Not included are 798 individuals with unknown transmission categories, 2 with unknown ages and 529 without a CD4-T exam prior to cART initiation. doi:10.1371/journal.pone.0095673.t003

\section{Availability of Data}

Proposals from external researchers to use our data are encouraged and welcomed, and requests will be analyzed by the Cohort Steering Committee that is composed of the Cohort Principal Investigators. The use of data pertaining to the individual sites is restricted to the sites themselves. In all circumstances, the confidentiality of each participant's related data must be preserved.

\section{Ethics Statement}

This protocol was approved by the Institutional Review Boards (IRB) of the participating sites (Comitê de Ética em Pesquisa da Secretaria Municipal de Saúde de São Paulo, Comitê de Ética do Centro de Referência e Treinamento DST/Aids, Comitê de Ética em Pesquisa do Instituto de Pesquisa Clinica Evandro Chagas da Fundação Oswaldo Cruz, Comitê de Ética na Pesquisa em Saúde da Escola de Saúde Pública da Secretaria de Estado da Saúde do Rio Grande do Sul, Comitê de Ética em Pesquisa da Maternidade Climério de Oliveira da Universidade Federal da Bahia and Comissão de Ética para Análise de Projetos de Pesquisa do 
Hospital das Clínicas e da Faculdade de Medicina da Universidade de São Paulo), according to the Brazilian regulation for research with human subjects. In the first phase, the IRB waived the requirement for written informed consent and requested the confidentiality of the individual's data, which was ensured at all stages of the project. In the second phase, all participants provided written consent for participation in the study.

\section{Results}

\section{Cohort Profile and Follow-up}

The socio-demographic, clinical and immunological profiles of the 5,061 patients enrolled during the first phase of the study (those started on cART between 2003 and 2010) are shown in Table 2. There was a predominance of men (male/female ratio 1.7:1), and the mean age at enrollment was 36.9 years (SD 9.9 years); 2,792 (55.2\%) patients had been infected with HIV via heterosexual contact, 1,193 (23.6\%) were in the homosexual/ bisexual exposure category, and 2,300 (45.4\%) were receiving cART at a treatment facility in the Southeast region.

As shown in Figure 2, the median duration of follow-up was 4.1 years (IQR 2.2-5.9 years; maximum 8.8 years). During a period of 8.8 years, $206(4.1 \%$ of the 5,061 cohort patients) were lost to follow-up, $345(6.8 \%)$ were censored due to transfer from the health care centers where they were being followed in the cohort, and 287 (5.7\%) had died. Therefore, the retention rate was $83.4 \%$, with 20,593.9 person-years (PY) of observation.

The largest proportion of patient loss $(104,50.4 \%)$ was observed in the first year of cohort follow-up, with reductions over time. The loss to follow-up rate ranged from 19.8 per 1,000 PY in the first 12 months to 1.1 per $1,000 \mathrm{PY}$ after the sixth year of observation, with an overall loss rate of 10.1 per 1,000 PY. The greatest risk of loss (Table 3) was observed for the health care centers located in the less developed regions (21.3 per 1,000 PY [North] and 10.9 per 1,000 PY [Northeast]), among young patients (18 to 25 years [14.0 per 1,000 PY] and 26 to 30 years [15.6 per 1,000 PY]), bisexuals (13.8 per 1,000 PY), those with no clinical manifestations after cART initiation (12.6 per 1,000 PY) and those with no history of cocaine use before cART initiation (12.1 per 1,000 PY).

\section{Characteristic of the Initial Treatment}

Information on the pre-cART immunological status is available for $89.6 \%$ of the patients, who presented with a mean and median nadir CD4 ${ }^{+}$T-cell count of 177.5 cells $/ \mathrm{mm}^{3}$ (SD 121.7 cells $/ \mathrm{mm}^{3}$ ) and 169.0 cells $/ \mathrm{mm}^{3}$ (IQR $75.0-250.0$ cells $/ \mathrm{mm}^{3}$ ), respectively. These values remained stable over the years evaluated $(\beta<-$ $0.001 ; p<0.99)$. The majority of patients $(53.4 \%)$ initiated cART with a nadir $\mathrm{CD} 4^{+} \mathrm{T}$-cell count $\leq 200 \mathrm{cells} / \mathrm{mm}^{3}$, and the $\mathrm{CD} 4^{+}$ $\mathrm{T}$-cell count at cART initiation was $\leq 350 \mathrm{cells} / \mathrm{mm}^{3}$ in $84.8 \%$ of the sample.

The initial treatment regimens prescribed were in line with the current recommendations of the Brazilian National Ministry of Health [36], and 28 cases (of the 5,061 cases) were identified in which inappropriate regimens were prescribed. Among the initial treatments, regimens involving non-nucleoside analogue reverse transcriptase inhibitors, boosted protease inhibitors and protease inhibitors without booster were prescribed for $64.2 \%, 24.1 \%$ and $10.1 \%$ of the patients, respectively. In $48.1 \%$ of the 5,061 cases, the first-line treatment regimen prescribed was zidovudine+ lamivudine+efavirenz (AZT+3TC+EFZ), whereas AZT+3TC+ lopinavir/ritonavir (AZT+3TC+LPV/r) and AZT+3TC+atazanavir/ritonavir (AZT+3TC+ATV/r) were used in $14.3 \%$ and $4.6 \%$, respectively. In the 2009-2010 period, there was an increase in the number of cases in which tenofovir was prescribed, $(11.6 \%$ in 2010).

The median number of regimens used per patient was 1 (IQR 1-2; mean 1.8), and the mean duration of the first-line regimens was 30.4 months $(95 \%$ CI $29.7-31.2)$. The number of individuals achieving viral suppression (VL $<400$ copies/ml [2003 to 2006] and $<50$ copies/ml [after 2007]) within the first 12 months after cART initiation was $77.4 \%$ (95\% CI 76.1-78.6). During the 6.5 years of observation, $88.2 \%$ (95\% CI 87.2-89.1) of the patients achieved viral suppression at some point after cART initiation. The lowest rates of viral suppression in the first year of cART were observed in individuals aged between 18 and 29 years $(66.2 \%)$, in transmission category injection drug use $(73.7 \%)$, with cocaine use before treatment $(74.1 \%)$, in service areas with lower economic development (North and Northeast regions, 61.3\% 73.3\%) and showing no adverse ARV events (85.2\%).

Nearly half $(45.4 \%)$ of the patients presented with HIV-related clinical manifestations after starting cART, and the most frequent were oral candidiasis and tuberculosis. The AIDS mortality rate for the period evaluated was 13.9 per 1,000 PY.

\section{Discussion}

The HIV-Brazil Cohort Study, with a long follow-up period and a significant number of observations, is an important asset to increase the availability of data on the countrywide outcomes of the National AIDS Program related to cART in public health care services. A special feature of our cohort is that HIV-infected individuals in Brazil have been exposed to a broad array of antiretroviral drugs-21 antiretroviral drugs of all classes (including 10 generic drugs) used in first-, second- and third-line treatment regimens [4]-for a longer period than patients from other resource-limited settings. Consequently, the results obtained from this cohort might be predictive of the effects that the longer-term use of cART will have in other middle- or low-income countries, where the regimens currently in use in Brazil have yet to be widely applied.

The characteristics of the HIV-Brazil Cohort Study facilitates analyses of the short-, medium- and long-term impact of using antiretroviral drugs in the context of the routine care of patients at publically funded health care centers, providing complementary evidence to that obtained through clinical efficacy trials. The evidence obtained from the analyses performed in this cohort will enable field evaluations and further improvement of the national public health policies [37].

The socio-demographic profile of the HIV-Brazil Cohort Study is similar to that represented by the cases of AIDS in adults reported to the Brazilian National Ministry of Health between 2003 and 2010 (Table 2). The two groups are also comparable in terms of the HIV transmission category and region of origin, although, proportionally, the HIV-Brazil Cohort Study included fewer individuals treated in the southern region of the country, resulting in a smaller representation of injection drug users.

The quality assessment of the data collected showed a satisfactory degree of completeness of the information for essential variables (Table 2). A lack of CD4+ T-cell counts prior to the initiation of cART was observed in 1 of 10 patients and was probably related to clinical decisions not to request this testing if the patient had a concomitant opportunistic infection at the time of cART initiation or during hospitalization. The epidemiological characteristics of individuals without baseline information on $\mathrm{CD} 4^{+} \mathrm{T}$-cell count, such as gender, age and transmission category, did not differ $(\mathrm{p}<0.05)$ from the other patients included in the cohort. Although the analysis of outcomes directly related to the 
CD4+ T-cell count showed few significant variations when excluding individuals without baseline information on CD4+ Tcell count, the mortality rate rose from 13.9 to 14.2 per 1,000 PY.

An important aspect to be highlighted is the relatively low rate of loss of follow-up, similar to what is observed in high-income countries and in the middle- and low-income countries reporting the lowest rates of loss of follow up $[38,39]$. The greater accuracy of this information was obtained through the linkage with national health information systems databases. These databases have high rates of coverage, gathering data from all HIV-infected patients linked to care and receiving ART nationwide, as well as the overall mortality data in the country [14]. Consequently, patients classified as lost to follow-up in the cohort have a high possibility of still being alive even without appearing for the clinical follow-up or are using cART from some other health service in the country.

The analysis presented in this article aims to outline the scope and potential use of the information derived from the HIV-Brazil Cohort Study. First-line non-nucleoside reverse-transcriptasebased regimens were the most prescribed first-line cART in Brazil and resulted in high levels of viral suppression in the first year of treatment, comparable to single-site observational studies $[20,23,24,40]$. This finding has reinforced the assumption that the use of cART in Brazilian health services has achieved results similar to other low- and middle-income countries [41-42].

The majority of patients presented with severe immunodeficiency $\left(\mathrm{CD} 4^{+}\right.$T-cell counts $\leq 200$ cells $/ \mathrm{mm}^{3}$ ) or AIDS-related diseases at cART initiation. This finding was higher than the results of previously reported studies that reviewed the clinical and immunological status at the time of arrival to the health services for initial clinical follow-up in Brazil [14]. Consequently, a higher proportion of late-onset cART in HIV-Brazil Cohort Study might have been caused by the loss of clinical follow-up before the initial prescription of cART.

\section{References}

1. Teixeira PR, Vitória MA, Barcarolo J (2004) Antiretroviral treatment in resource-poor setting: the Brazilian experience. AIDS (suppl 3): S5-S7.

2. Hacker MA, Kaida A, Hogg RS, Bastos FI (2007) The first tem years: achievements and challenges of the Brazilian program of universal access to HIV/AIDS comprehensive management and care, 1996-2006. Cad Saúde Pública (suppl 3): S345-59.

3. Okie S (2006) Fighting HIV: lessons from Brazil. N Engl J Med 354(19): 197781 .

4. Nunn AS, Fonseca EM, Bastos FI, Gruskin S (2009) AIDS Treatment In Brazil: impacts and challenges. Health Affairs 28(4): 1103-13.

5. Greco DB, Simão M (2007) Brazilian policy of universal access to AIDS treatment: sustainability challenge and perspectives. AIDS (suppl 4): S37-S45.

6. Pacheco AG, Tuboi SH, Faulhaber JC, Harrison LH, Schechter M (2008) Increase in non-AIDS related conditions as causes of death among HIV-infected individuals in the HAART era in Brazil. PLoS One 3(1): e1531.

7. Rezende ELLF, Vasconcelos AMN, Pereira MG (2010) Causes of death among people living with HIV/AIDS in Brazil. Braz J Infect Dis 14(6): 558-563.

8. Belloso WH, Orellana LC, Grinsztejn B, Madero JS, La Rosa A, et al. (2010) Analysis of serious non-AIDS events among HIV-infected adults at Latin American sites. HIV Medicine 11(9): $554-64$.

9. Veras MASM, Ribeiro MCA, Jamal LF, McFarland W, Bastos FI, et al. (2011) The "AMA-Brazil" cooperative project: a national-wide assessment of the clinical and epidemiological profile of AIDS-related deaths in Brazil in the antiretroviral treatment era. Cad Saude Pública (suppl 1): S104-S113.

10. Guibu IA, Barros MBA, Donalísio MR, Tayara A, Alves MCGP (2011) Survival of AIDS patients in the Southeast and South of Brazil: analysis of the 1998-1999 cohort. Cad Saúde Pública (suppl 1): S79-S92.

11. Silva ACAL, Rodrigues BSC, Micheletti AMR, Tostes S, Meneses ACO, et al. (2012) Neuropathology of AIDS: an autopsy review of 284 cases from Brazil comparing the finding pre- and post-HAART (highly active antiretroviral therapy) and pre- and post-mortem correlation. AIDS Research and Treatment DOI: $10.1155 / 2012 / 186850$.

12. Grinsztejn B, Luz PM, Pacheco AG, Santos DV, Velasque L, et al. (2013) Changing mortality profile among HIV-infected patients in Rio de Janeiro, Brazil: shifting from AIDS to non-AIDS related conditions in the HAART era. PLoS One 8(4): e59768.
It is also noteworthy that the mean CD4+ T-cell count at the beginning of cART did not show a trend of increase over time, indicating the urgent need for increased access to earlier HIV diagnosis and linkage to care countrywide, considering the fact that Brazil has a concentrated epidemic in social sectors with a high degree of stigma and a pattern of service use that is more restricted than in the general population $[32,33]$.

Another important aspect is the fact that the worst results were observed in regions with the lowest economic development levels in the country, indicating that the reduced ability of these regions to obtain optimal results from the therapies available for AIDS may lead to an increase in the health inequalities existing in the country through increase HIV incidence and HIV-associated mortality.

The study design, characteristics of patients included and the initiation of cART presented in this paper show the scope of investigation conducted by the HIV-Brazil Cohort Study, which is the main initiative to analyze the effects of cART use in public health services in the country. Thus, the results shown herein and those yet to be produced can contribute to advancing the knowledge generated from clinical trials, particularly considering the context of medium- and low-income countries, which in recent years have greatly expanded their programs to access cART. This is important in the formulation of better health policies for the needs of people living with HIV in resource-constrained situations.

\section{Author Contributions}

Conceived and designed the experiments: AG MME RAS AOK VV MLRI NTB GB UT NOL CALS HRL BG EAC. Performed the experiments: RAS AOK VV NTB CB BG MLRI UT NOL CALS HRL. Analyzed the data: AG MME AJFC EAG. Wrote the paper: AG MME AJFG RAS AOK VV MLRI NTB CB UT NOL CALS HRL BG EAG.

13. Torres TS, Cardoso SW, Velasque LS, Marins LM, Oliveira MS, et al. (2013) Aging with HIV: an overview of an urban cohort in Rio de Janeiro (Brazil) across decades of life. Braz J Infect Dis 17(3): 324-31.

14. Grangeiro A, Escuder MM, Menezes PR, Alencar R, Gastilho EA (2011) Late entry into HIV care: estimated impact on AIDS mortality rates in Brazil, 20032006. PLoS One 6(1): e14585.

15. Malta M, Bastos FI, Silva CMFP, Pereira GF, Lucena FF, et al. (2009) Differential survival benefit of universal HAART access in Brazil: a nationalwide comparison of injection drug users versus men who have sex with men. JAIDS 52(5): 629-35.

16. Portela MC, Lotrowska M (2006) Heath Care to HIV/AIDS patients in Brazil. Rev Saúde Pública 40(suppl): 70-79.

17. Soares MA, Brindeiro RM, Tanuri A (2004) Primary HIV-1 drug resistance in Brazil. AIDS (suppl 3): S9-S13.

18. Inocêncio LA, Pereira AA, Sucupira MCA, Fernandes JCC, Jorge CP, et al. (2009) Brazilian Network for HIV Drug Resistance Surveillance: a survey of individuals recently diagnosed with HIV.J Int AIDS Soc 12: 20. DOI: 10.1186/ 1758-2652-12-20.

19. Maruza M, Albuquerque MFPM, Braga MC, Barbosa MTS, Byington R, et al. (2012) Survival of HIV-infected patients after starting tuberculosis treatment: a prospective cohort study. Int J Tuberc Lung Dis 16(5): 618-24.

20. Ribeiro FA, Tupinambás U, Fonseca MO, Greco DB (2012) Durability of the combined antiretroviral regimen in patients with AIDS at a reference center in Belo Horizonte, Brazil, from 1996 to 2005. Braz J Infect Dis 16(1): 27-33.

21. Alencastro PR, Fuchs SC, Wolf FH, Ikeda LM, Brandão ABM, et al. (2011) Independent predictors of metabolic syndrome in HIV-infected patients. AIDS Patient Care STDs 25(11): 627-634.

22. Miranda A, Morgan M, Jamal L, Laserson K, Barreira D, et al. (2005) Impact of antiretroviral therapy on the incidence of tuberculosis: the Brazilian experience, 1995-2001. PLoS ONE 2(9): e826. DOI: 10.1371/journal.pone.0000826.

23. Hofer CB, Schechter M, Harrison LH (2004) Effectiveness of antiretroviral therapy among patients who attend public HIV clinics in Rio de Janeiro, Brazil. J Acquir Immune Defic Syndr 36(4): 967-71.

24. Medeiros R, Diaz RS, Filho AC (2002) Estimating the length of the first antiretroviral therapy regiment durability in São Paulo Brazil. BJID 6(6): 298304. 